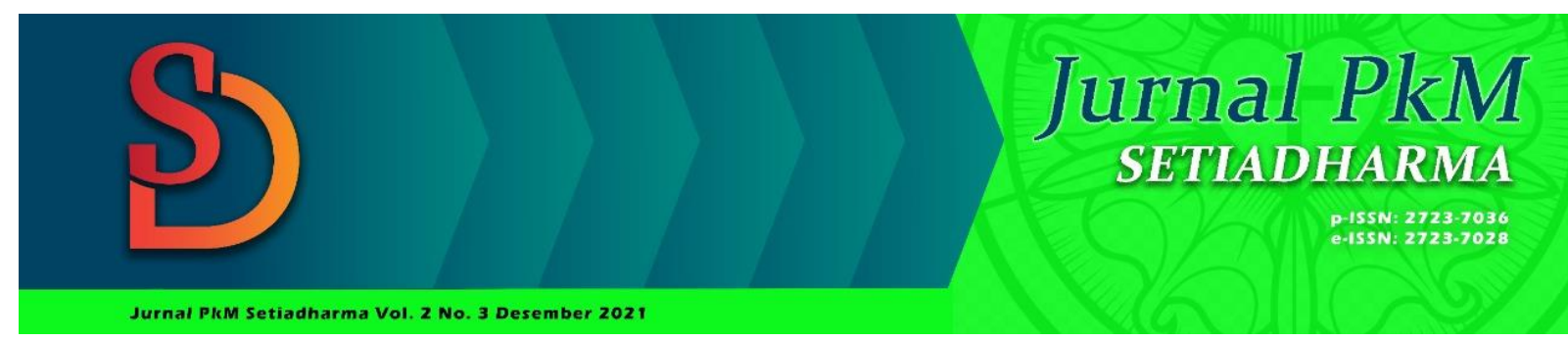

\title{
PEMBERITAAN KABAR BAIK MELALUI RADIO KHARISMA BANDUNG
}

\author{
Yanto Paulus Hermanto \\ Sekolah Tinggi Teologi Kharisma Bandung \\ yantopaulush@gmail.com
}

Diterima:
05-07-2021
Direview:
24-09-2021
16-10-2021
Direvisi:
06-10-2021
08-11-2021
Diterbitkan:
31-12-2021
Keywords:
Preaching, gospel,
radio, teaching,
systematic
Kata Kunci:
Pemberitaan,Injil,
radio, pengajaran,
sistematis

\section{Abstract}

The call to preach the good news is an urgent matter so that mankind's biggest problem, namely sin, can be resolved. The Bible begins by describing the tragic human condition, a situation only the Bible can answer. Through the gospel, human sins can be resolved and humans can return to peace with God. The preaching of the gospel must be done because it is God's desire that all sinful humans can be saved from eternal punishment. STT Kharisma to meet these goals in collaboration with radio kharisma. And committed to preaching the good news every week to Kharisma 828 AM radio listeners. The method used in delivering this good news is by means of lectures, and interactive discussions both with charisma radio listeners and with other sources. Of course the target is so that charismatic radio listeners can grow spiritually. The procedure for preaching the good news is planned in such a way as to be structured and systematic so that it is easy to understand and understand. And finally the message recipients (charisma radio listeners) can get to know the Lord Jesus and grow spiritually.

\footnotetext{
Abstrak

Panggilan pemberitaan kabar baik merupakan hal yang mendesak supaya masalah terbesar manusia yaitu dosa dapat teratasi. Alkitab mulai dengan menjelaskan keadaan manusia yang tragis, suatu keadaan yang hanya dapat terjawab oleh Injil. Melalui Injil dosa manusia dapat terselesaikan dan manusia dapat kembali berdamai dengan Allah. Pemberitaan Injil harus dilakukan karena merupakan keinginan Allah agar semua manusia berdosa dapat diselamatkan dari hukuman kekal. STT Kharisma untuk memenuhi tujuan tersebut bekerja sama dengan radio kharisma. Dan berkomitmen untuk memberitakan kabar baik setiap minggunya kepada para pendengar radio Kharisma $828 \mathrm{AM}$. Metode yang digunakan dalam penyampaikan berita kabar baik ini dengan cara ceramah, dan diskusi interaktif baik dengan pendengar radio kharisma maupun dengan nara sumber lain. Tentu sasarannya adalah agar para pendengar radio kharisma dapat bertumbuh secara rohani. Tata laksana pemberitaan kabar baik direncanakan sedemikian rupa supaya terstruktur dan sistematis sehingga mudah dimengerti dan dipahami. Dan akhirnya para penerima pesan (pendengar radio kharisma) dapat mengenal Tuhan Yesus dan bertumbuh secara rohani.
} 


\section{PENDAHULUAN}

Perkembangan teknologi multimedia telah menjanjikan potensi besar dalam merubah cara seseorang untuk belajar, untuk memperoleh informasi, dan menyesuaikan informasi tersebut. Media sosial juga menyediakan peluang bagi pendidik untuk mengembangkan teknik pembelajaran sehingga menghasilkan hasil yang maksimal. ${ }^{1}$ Demikian juga bagi peserta didik, dengan teknologi yang berkembang terus diharapkan akan lebih mudah untuk menentukan dengan apa dan bagaimana mereka dapat menyerap informasi secara cepat dan efisien. Sumber informasi tidak lagi terfokus pada teks dari buku semata tetapi lebih luas dari itu. Kemampuan teknologi multimedia yang telah terhubung internet semakin menambah kemudahan dalam mendapatkan informasi yang diharapkan.

Beberapa media yang selama ini digunakan oleh STT Kharisma dalam menyampaikan kebenaran firman Allah melalui instagram, facebook, twitter, web dan juga melalui radio baik FM maupun AM. Untuk penerima pesan yang sudah mengikuti perkembangan zaman dengan internet maka tentu akan lebih mudah menggunakan IG, FB, twitter dan web. Namun bagi bagi mereka yang tidak memiliki kuota internet yang cukup bahkan belum memahami, maka radio merupakan salah satu sarana yang masih perlu dipertahankan.

Radio merupakan media yang tetap eksis saat ini meskipun di era internet. Bahkan dengan menyatukan gelombang radio dan internet dalam pengelolaannya dapat memperluas penetrasi ke masyarakat. Menurut survei Nielsen Indonesia tahun 2017 menyatakan bahwa penetrasi melalui radio menempati urutan keempat dibanding media lain. Televisi masih menduduki urutan pertama dengan penetrasi $96 \%$. Kedua media luar ruang dengan penetrasi 53\%, ketiga, internet $44 \%$, keempat, radio dengan penetrasi 37\%, koran7\% dan tabloid 3\%. ${ }^{2}$ Dengan demikian peran radio masih sangat berdampak bagi masyarakat Indonesia dan bisa digunakan dalam pemberitaan kabar baik.

Ada beberapa penerima pesan yang setia yang masih belum tersentuh dengan teknologi internet; mereka masih konservatif dengan gelombang radio yakni sekitar 37 $\%$ dari masyarakat. ${ }^{3}$ Oleh sebab itu STT Kharisma mempertimbangkan untuk terus menggunakan media radio ini bagi pemberitaan kabar baik. Meskipun tetap memadukan dengan teknologi yang bisa dijangkau oleh lebih banyak orang, yakni melalui instagram maupun facebook secara live streaming.

Umumnya para pendengar radio kharisma yang mendengar melalui gelombang radio adalah mereka orang-orang pinggiran kota atau di pulau-pulau terpencil yang sederhana dan mereka adalah pendengar radio yang setia. Sedangkan yang mendengar melalui media seperti instagram dan facebook adalah orang-orang yang mulai agak ke perkotaan, tetapi mereka adalah pendengar-pendengar yang loyal dari sejak lama dengan latar belakang yang berbeda-beda, baik suku, agama maupun budaya.

Berdasarkan pertimbangan ini STT kharisma terus melakukan pemberitaan kabar baik ini dan bekerja sama dengan radio Kharisma $828 \mathrm{AM}$. Radio kharisma adalah radio yang mempertahankan dengan gelombang amplitude modulation. Dengan gelombang AM ini bisa menjangkau lebih jauh hingga ke desa-desa dan pulau-pulai lain yang belum terjangkau. Dengan memadukan gelombang radio AM dan media diharapkan bukan saja menjangkau para penerima pesan yang konservatif tapi juga menjangkau para pengguna teknologi terbaru.

\footnotetext{
${ }^{1}$ Arozatulo Telaumbanua, "E-Misi : Aplikasi Penginjilan Berbasis Teknologi," Prodising (2020).

${ }^{2}$ KPI, "Survey Nielsen Indonesia 'Penetrasi Media,"' 2017.

3 Ibid.
} 


\section{METODE PELAKSANAAN}

STT kharisma melaksanakan pengabdian masyarakat melalui radio kharisma diawali dari 10 Januari 2018 hingga sekarang. Adapun yang dilakukan oleh STT kharisma adalah menyediakan nara sumber untuk acara kharisma blessing setiap hari Sabtu setiap minggunya dari pukul 07.00 - 09.00 WIB. Acara kharisma blessing ini merupakan acara khusus untuk memberikan siraman rohani bagi para pendengar baik yang melalui gelombang $828 \mathrm{AM}$ maupun media sosial (instagram dan facebook) secara live. Siraman rohani ini merupakan pengajaran secara sistematis untuk menolong pendengar mengerti dasar-dasar iman dan bagaimana mereka bertumbuh secara rohani. Metode yang digunakan dalam pemberitaan kabar baik melalui ceramah dan diskusi interaktif dengan para pendengar radio dan nara sumber lainnya. Diharapkan melalui metode ini akan mendorong penambahan para pendengar radio kharisma, namun juga penyampaian kabar baik lebih efektif. Ada pun strategi untuk mencapai hal ini, STT Kharisma menyiapkan materi yang sistematis dengan peyampaikan pesan yang menarik dan dengan judul-judul renungan yang menarik. Kemudian apa yang akan disampaikan tersebut dipromosikan secara luas baik melalui acara-acara radio kharisma lain yang pendengarnya cukup bervariasi dan yang bersifat umum, serta melalui media lain seperti facebook, Instagram, whatapp grup, twitter dan lain-lain.

\section{PEMBAHASAN DAN HASIL}

Hal-hal inti yang akan disampaikan dalam pembahasan ini meliputi sasaran yang akan dicapai dalam siraman rohani, perencanaan pengajaran dan bagaimana pelaksanaaannya. Ketiga hal ini akan memperjelas arah pengabdian masyarakat yang dilakukan STT Kharima Bandung melalui program di radio Kharisma.

\section{Sasaran Siraman Rohani di Radio Kharisma Bandung}

Sasaran akhir dari acara siraman rohani di radio Kharisma adalah terjadinya pertumbuhan rohani dari para pendengarnya. Pertumbuhan rohani ini sangat penting dan menjadi fokus setiap pemberitaan. Pemberitaan kabar baik ini sebaiknya terstruktur mulai dari proses awal sampai akhir. Pemberitaan yang terstrutur tidak terlepas dari proses pembelajaran yang baik. Pembelajaran yang baik akan membuat pendengar radio Kharisma bertumbuh secara rohani. Pertumbuhan rohani ini merupakan suatu proses yang diawali sejak seseorang dilahirkan kembali secara rohani. Menurut Evelyn Christenson pertumbuhan ini merupakan suatu proses yang tidak pernah berakhir bagi orang Kristen. ${ }^{4}$ Berarti selama hidup merupakan proses pertumbuhan. Dengan demikian sasaran acara ini sangatlah tepat dan bisa berkesinambungan.

Sasaran awal siraman rohani yang dilakukan STT Kharisma di radio kharisma adalah agar para pendengar mengalami kelahiran baru. Sasaran awal ini sangatlah penting dan menjadi titik awal seseorang bisa mengalami pertumbuhan rohani. Tanpa seseorang mengalami kelahiran baru, maka tidak mungkin akan mengalami pertumbuhan. ${ }^{5}$ Dengan demikian siraman rohani yang disampaikan selama beberapa kali adalah berkaitan dengan bagaimana para pendengar radio kharisma mengalami

\footnotetext{
${ }^{4}$ Evelyn Christenson, Pola Hidup Kristen, Berubah (Bandung: Kalam Hidup, 2002).

5 Yanto Paulus Hermanto, KATEKETIKA: BAGAIMANA GEREJA YANG MENUMBUHKAN ROHANI \& MENINGKATKAN PERAN MISI JEMAAT, 1st ed. (Purwokerto: pena persada, 2021).
} 
kelahiran baru.

Setelah sasaran awal tersampaikan dengan baik maka, proses pembinaan berlanjut dengan sasaran agar para pendengar mengalami pertumbuhan rohani. Sekolah Tinggi Teologi Kharisma Bandung sebagai penyampai acara siraman rohani berkewajiban untuk memikirkan dan membawa para pendengar radio kharisma ke level rohani yang lebih tinggi. ${ }^{6}$ Sasaran ini harus menjadi prioritas utama dalam penyampaian siraman rohani. Untuk itu maka perlu pemahaman yang jelas secara detail mengenai pengertian kelahiran kembali, proses kelahiran kembali, bagaimana ciri-ciri orang yang sudah mengalaminya, langkah-langkah agar mengalami pertumbuhan rohani dan ciri-ciri seseorang yang sedang dan sudah mengalaminya. ${ }^{7}$ Pembinaan yang demikian yang merupakan sasaran yang diharapkan ketika acara siraman rohani ini dilaksanakan.

Pertumbuhan jasmani merupakan suatu proses yang dimulai dari sejak manusia ada di dalam kandungan seorang ibu, lahir ke bumi, menjadi bayi, kanak-kanak, pubertas dan dewasa. Begitu pun pertumbuhan rohani merupakan proses yang dimulai sejak seseorang mengalami kelahiran baru di dalam Kristus, kanak-kanak rohani, akil balig, dewasa, sampai menjadi serupa dengan Kristus. ${ }^{8}$ Menurut Eugene Peterson pertumbuhan ini terjadi secara tidak disadari dan misterius. Orang-orang di sekitarnya pun terkadang tidak menyadari hal tersebut. Yang penting orang yang lahir baru tersebut menjalani kehidupan beriman secara alkitabiah, maka pertumbuhan menjadi sesuatu yang paling wajar terjadi. ${ }^{9}$ Dengan demikian sebagai penyampai siraman rohani, STT Kharisma pun berpegang pada hal ini. STT Kharisma Bandung merancang sedemikian rupa pembelajarannya namun proses pertumbuhan para pendengarnya diserahkan sepenuhnya kepada Tuhan yang akan memberi pertumbuhan. Sebagai penyampai kabar baik, menyampaikan secara sistematis, menarik dan sejelas mungkin, selebihnya berharap dan bersandar pada karya dari Roh Kudus.

Pertumbuhan yang paling baik terjadi secara otomatis sebagai hasil pemberian makanan secara rutin dan teratur. ${ }^{10}$ Pemberian makanan merupakan hal yang wajib dilakukan agar mengalami pertumbuhan. ${ }^{11}$ Yang dimaksud makanan rohani adalah firman Allah. Dalam King James Version :"Thy words were found, and I did eat them ..." Nabi Yeremia mengatakan, firman-firman-Nya yang ditemukan, ia memakannya. Jadi firman Tuhan itu seperti makanan. Ada beberapa yang dicatat Alkitab mengenai firman Tuhan sebagai makanan, kesatu susu (1Pet. 2:2). Susu mengandung protein dan sangat baik untuk pertumbuhan anak. Kedua, roti (Mat. 4:4), roti mengandung karbohidrat dan sangat baik agar yang memakannya menjadi kuat. Ketiga, makanan keras buat orang dewasa (Ibr. 5:13-14). Makanan disajikan bagi mereka yang memiliki panca indra yang sudah terlatih dan mengetahui kehendak Allah. Keempat, madu (Mzm. 119:103), janji Tuhan manis seperti madu untuk dinikmati. Dengan demikian gereja yang menginginkan jemaatnya bertumbuh harus menyediakan makanan rohani yang berkualitas, yakni melalui pengajaran firman Allah yang sudah terencana dengan baik.

\footnotetext{
${ }^{6}$ Arozatulo Telaumbanua, "Peran Gembala Sidang Sebagai Pendidik Dalam Pertumbuhan Rohani Jemaat," FIDEI: Jurnal Teologi Sistematika dan Praktika (2019).

7 Yanto Paulus Hermanto, KATEKETIKA: BAGAIMANA GEREJA YANG MENUMBUHKAN ROHANI \& MENINGKATKAN PERAN MISI JEMAAT.

8 Tiur Imeldawati and Yayan Erina Br. Regar, "Prinsip Pertumbuhan Rohani Dalam Efesus 5:1-21 Dan Korelasinya Dalam Mengupayakan Pertumbuhan Rohani Jemaat GPdI Gunung Moria Bedagai," Jurnal Christian Humaniora (2021).

${ }_{9}^{9}$ Eugene Peterson, Pola Hidup Kristen, Bertumbuh Sebagai Orang Kristen Yang Sehat (Bandung: Kalam Hidup, 2002).

${ }^{10}$ Mika Mika and Petronella Tuhumury, "Implementasi Strategi Pembinaan Menuju Pertumbuhan Rohani Pemuda Gkii Jemaat Sidu'ung Muara Berau," Jurnal Jaffray (2013).

${ }^{11}$ Calvin Miller, Pola Hidup Kristen, Mengukur Pertumbuhan Kita (Bandung: Kalam Hidup, 2002).
} 
Firman Allah ini yang menjadikan jemaat bertumbuh secara otomatis. ${ }^{12}$ Makanan seperti inilah yang disampaikan oleh STT Kharisma Bandung. Dari mulai makanan buat bayi hingga makanan bagi orang Dewasa. Semuanya ditujukan untuk menyasar pertumbuhan rohani para pendengar radio kharisma.

Menurut Miller pertumbuhan selalu berhubungan dengan pemeliharaan dan latihan. Pemeliharaan dalam arti adanya makanan yang cukup dan latihan teratur setiap hari. Jika seorang anak berbaring di tempat tidur tiap hari, maka otot-ototnya menjadi lemah dan tidak bertumbuh dengan maksimal. Oleh sebab itu menurutnya seseorang bisa mengalami pertumbuhan rohani bila setiap hari rohaninya diisi dengan kebenaran firman Tuhan dan hidupnya terus dilatih untuk menerapkan kebenaran yang telah dipelajarinya tersebut. ${ }^{13}$ Dengan demikian pertumbuhan rohani setiap orang akan berbeda-beda tingkat kecepatannya, sebab hal itu bergantung pada seberapa besar firman Tuhan yang diserap dan juga ketaatannya pada firman yang telah diserapnya tersebut. Seorang jemaat yang bertumbuh akan semakin terlihat dalam kehidupannya setiap hari dengan karakternya yang semakin diubah menjadi seperti Kristus. Dengan kenyataan seperti ini, maka secara langsung orang lain yang belum mengenal Kristus akan melihat perubahan dan sikap hidup yang terpuji dari orang yang bertumbuh tersebut. Ini pun yang menjadi sasaran dari STT Kharisma Bandung dalam acara siraman rohani di radio Kharisma.

Sasaran lain yang harus menjadi sasaran acara siraman rohani adalah perubahan dalam diri pendengar radio kharisma. Perubahan sikap, karakter dan perilaku merupakan ciri seseorang bertumbuh secara rohani. Orang percaya yang bertumbuh akan dengan mudah menjadi saksi dan dapat diterima dengan baik ketika memberitakan kabar baik kepada orang-orang di lingkungannya. ${ }^{14}$ Transformasi akibat respons terhadap pemberitaan kabar baik Itulah yang menjadi sasaran acara siraman rohani ini. Dan ini memerlukan usaha yang terus menerus dan dalam jangka waktu yang panjang.

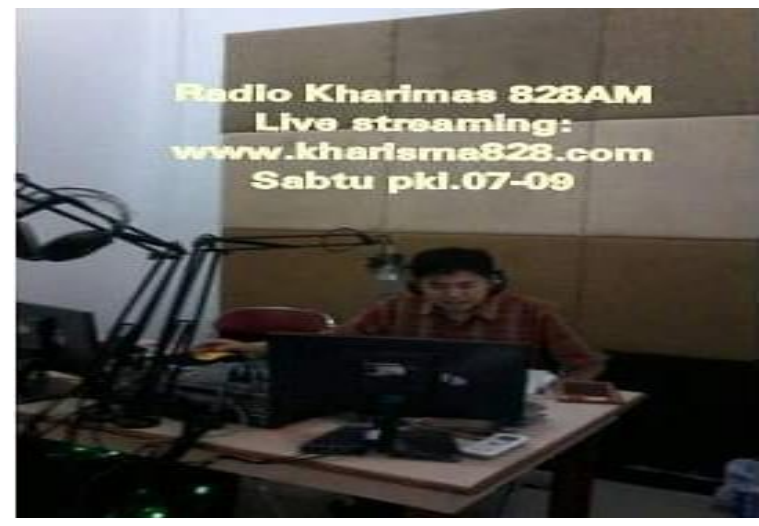

\section{Perencanaan Pengajaran dalam Siraman Rohani di Radio Kharisma}

Sasaran yang akan dicapai dalam acara siraman rohani memerlukan perencanaan pengajaran yang serius. Perencanaan ini harus menyusun dengan tepat dan sistematis sehingga sasaran dapat tercapai secara maksimal. Perencanaan ini mengikuti kaidah-

12 Haryadi Baskoro and Hendro Hariyanto Siburian, "Keseimbangan Pertumbuhan Spiritual Dan Intelektual: Teladan Yesus Dan Paulus Bagi Hamba Tuhan Masa Kini," FIDEI: Jurnal Teologi Sistematika dan Praktika (2019).

${ }^{13}$ Calvin Miller, Pola Hidup Kristen, Mengukur Pertumbuhan Kita.,74

${ }^{14}$ AGUNG GUNAWAN, “PEMURIDAN DAN KEDEWASAAN ROHANI,” SOLA GRATIA: Jurnal Teologi Biblika dan Praktika (2020). 
kaidah perencanaan dalam pembelajaran pendidikan. Sehingga harus memperhatikan berbagai komponen pembelajaran. Komponen pembelajaran meliputi metode, bahan ajar, pengajar, media ajar dan evaluasi ${ }^{15}$ Oleh sebab itu dalam perencanaan pembelajaran, STT Kharisma melaksanakan komponen pembelajaran pendidikan tersebut.

Metode yang digunakan dalam siraman rohani menggunakan berbagai metode. Yang penting melalui metode ini pendengar semakin jelas dan memahami apa yang disampaikan. ${ }^{16}$ Untuk siraman rohani di radio, maka STT Kharisma lebih merencanakan metode ceramah dan diskusi interaktif dengan pendengar radio dan nara sumber. Dengan demikian persiapan untuk siraman rohani lebih fokus dan terarah.

Bahan ajar disusun sesuai dengan sasaran yang akan dicapai. Bahan ajar ini yang diberikan secara berkelanjutan, dievaluasi dan diperbarui setiap tiga bulan sekali. Hal ini dimaksudkan agar bahan ajar tidak menyimpang dari sasaran yang telah ditetapkan dan bisa lebih efektif. Bahan pengajaran yang dilaksanakan menyasar terhadap peningkatan pertumbuhan rohani jemaat, dan setelah itu diharapkan para pendengar radio terlibat dalam misi. ${ }^{17}$ Yakni menjangkau dan mengajak tetangga atau orang-orang yang mereka kenal untuk mendengarkan juga acara siraman rohani di radio Kharisma.

Bahan pengajaran yang disiapkan adalah bagaimana agar para pendengar radio kharisma mengalami kelahiran baru. ${ }^{18}$ Diawali dari kejatuhan manusia pertama dalam dosa (Kej. 2:7-17; 3:1-19; Rm. 5:12), manusia kedua dari Tuhan sebagai pengganti manusia pertama yang gagal (Mat. 1:18-25; Fil. 2:5-11; Ef. 1:20-23; 1Pet. 2:21), bagaimana agar manusia mengalami kelahiran baru (Yoh. 3:1-21; 1:10-13, 8:32-44), Bagaimana manusia mengalami pemulihan dari luka batin (Mzm. 109:22; 1Sam. 1:411) ${ }^{19}$, Bagaimana agar para pendengar terlepas dari berbagai ikatan lama dalam hidupnya (Yoh. 8:34; 1Tim. 6:10; 1Kor. 6:13; Mrk. 10:35-45). ${ }^{20}$ Setelah bahan ajar ini disampaikan diharapkan para pendengar benar-benar sudah mengalami kelahiran baru dan mereka siap untuk bertumbuh.

Pengajaran berikutnya adalah bagaimana agar para pendengar radio kharisma mengalami pertumbuhan rohani. ${ }^{21}$ Diawali dengan pengajaran agar para pendengar radio kharisma kesukaannya adalah membaca Alkitab (Yer. 15:16; Mat. 4:4; 1Pet. 2:2; Mzm. 119:9-11; 2Tim. 3:16-17), kesukaannya hidup dalam doa (Mrk. 1:35; Luk.6:12; 22:40; Yak. 5:16), Kesukaannya beribadah kepada Tuhan (Kis. 2:46-47; 5:42; Ibr. 10:2425; Kol. 3:22-25), dan mereka mampu mendisiplin pikiran (Mzm. 139:23; 2Kor. 10:5; 11:3; Fil. 2:5; 3:19). Setelah pelajaran-pelajaran ini, diharapkan para pendengar radio kharisma mulai mengalami pertumbuhan dan mengalami perubahan karakter dan perilaku dalam kehidupannya.

Pengajaran berikutnya dimulai dengan menyampaikan nilai-nilai kekristenan yang harus menjadi ciri khas dalam kehidupannya sehari-hari. ${ }^{22}$ Pengajaran mengenai kejujuran (Ams. 2:21; 14:11; 15:8; 16:17; 21:8; 22:8; Kel. 23:8; 20:3; Ul. 16:19) ${ }^{23}$,

\footnotetext{
15 Jarosław Horowski, “Christian Religious Education and the Development of Moral Virtues: A NeoThomistic Approach," British Journal of Religious Education (2020).

${ }^{16}$ Lois E. Lebar, Education That Is Christian (Proses Belajar Mengajar Kristiani \& Kurikulum Yang Alkitabiah), ed. Tjuk S. Kaihatu, 2nd ed. (Jakarta: Penerbit GAndum Mas, 2006).

${ }^{17}$ Harjanto, Perencanaan Pengajaran (Jakarta: PT. Rangga Karya, 2008).

18 Yanto Paulus Hermanto, KATEKETIKA: BAGAIMANA GEREJA YANG MENUMBUHKAN ROHANI \& MENINGKATKAN PERAN MISI JEMAAT.

${ }^{19}$ Pieter Lase, Katekisasi Umum Menyibak Tabir Kebenaran (Malang: Gandum Mas, 2014).

${ }^{20}$ Ibid., 109-111.

21 Yanto Paulus Hermanto, KATEKETIKA: BAGAIMANA GEREJA YANG MENUMBUHKAN ROHANI \& MENINGKATKAN PERAN MISI JEMAAT.

22 Ibid.

23Ibid., 116-117.
} 
integritas (1Yoh. 2:5-6; 3:18; Yak. 1:22; 1Tim. 4:12; Kol. 3:23; Rm. 14:8) ${ }^{24}$, mengasihi Tuhan (Mat. 22:37; Kis. 5:26-32, 40-42; Dan. 3:17-18; Yoh. 14:21; Ul. 30:15-16)25, mengasihi sesama (1Kor. 13:4-7; Gal. 5:22; 6:10; Mat. 7:20; Yoh. 10:15; Kis. 2:41-47) ${ }^{26}$, Hidup dalam perdamaian (Mat. 5:39-42; 18:22; 26:52-53; Rm. 12:18-19; 1Tes. 5:13; Ibr. 12:14; Kol. 3:13, 19), hidup dalam kerendahan hati (Mat. 11:29; Fil. 2:3; Mzm. 25:9; 37:11; 69:32; 149:4; Ul. 8:2-3), hidup dalam kekudusan (Im. 11:44; 1Pet. 1:15-16; Ibr. 12:14; Yos. 3:5; Ams. 15:3; Yer. 16:17), Ketekunan (Rm. 12:12; Kol. 4:2; Luk. 18:1; Kis. 14:22; Kol. 1:23; Why. 2:10), hidup dalam ketaatan (Ibr. 4:15; 11:8; 13:5; Kis. 5:29; why. 2:10; Fil. 2:5-8), pendengar radio kharisma dapat membangun relasi dengan baik (1Kor. 1:10; 13:7; Kis. 2:46; Fil. 2:3-4; Mat. 6:12-15), pendengar radio kharisma mengalami perubahan perilaku (Mat. 7:16, 20; 12:33; Gal. 5:22; Ayb. 1:1; Ams 3:7; 4:27; 1Tes. 4:3; 1Kor. 3:16; 5:9; 10:23), menjadi teladan dalam perkataan sehari-hari (Yak. 1:19; Ef. 4:29; Ams. 15:1; Pkh. 5:1-6; Ams. 6:2, 19, Mat. 15:18) dan pendengar tetap beriman dalam penderitaan (2Tim. 3:12; 1Pet. 2:19, 21; Luk. 9:23-24; Flp. 4:11-13). Melalui pengajaran ini, para pendengar menjadi orang-orang yang siap untuk bertumbuh dewasa dengan pengenalan yang semakin mendalam kepada Tuhan.

Pengajaran ini akan terus berlanjut hingga para pendengar menjadi umat Tuhan yang dewasa secara rohani dan mereka menjadi umat Tuhan yang misioner. Diharapkan melalui pengajaran di radio kharisma ini, pendengarnya menjadi orang-orang yang tangguh di dalam Tuhan dan menjangkau orang lain bagi Kristus.

\section{Pelaksanaan Siaran di Radio Kharisma 828 AM Bandung}

Perencanaan pengajaran yang disusun setiap tiga bulan ini disampaikan kepada pendengar radio di gelombang 828 AM secara berurut dan sistematis setiap hari sabtu dari pukul 07.00 sampai pukul 09.00, dengan nama acara Kharisma Blessing. Melalui pelaksanaan siaran ini diharapkan setiap pendengarnya mendapat pengenalan akan Tuhan dan bertumbuh secara rohani. Dari feed back pendengar melalui WA chat radio atau telepon ke studio radio kharisma, mereka merasa diberkati dengan siraman rohani di acara kharisma blessing ini. Penyiar tetap untuk acara kharisma Blessing ini adalah dosen STT Kharisma, yakni Yanto Paulus Hermanto. Penulis juga biasanya mengajak dosen lain atau mahasiswa tingkat akhir untuk menyampaikan testimony berkaitan dengan pengajaran yang disampaikan. Dengan demikian acara ini juga bisa membuat dosen dan mahasiswa di lingkungan STT Kharisma menjadi berkat untuk orang di luar lingkungan STT Kharisma.

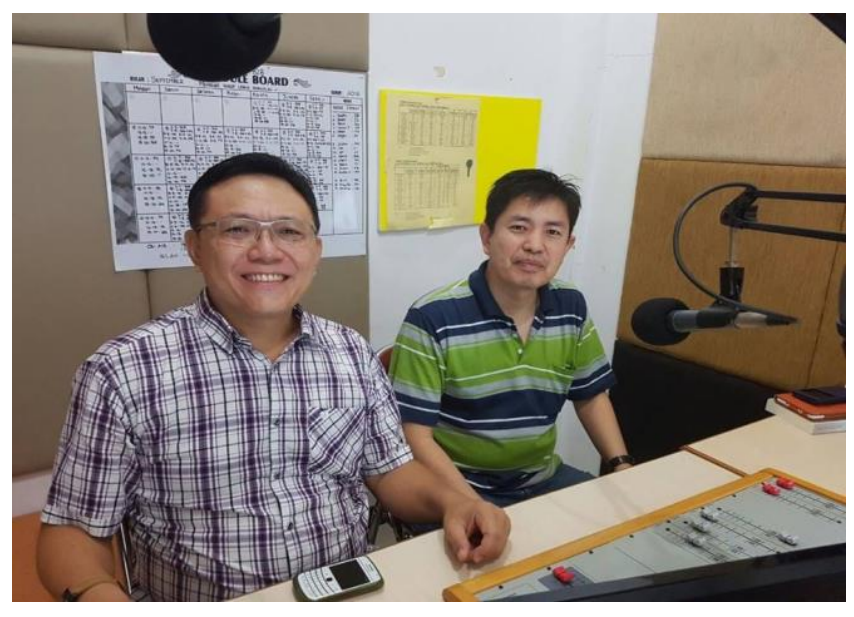

24Ibid., 126-128.

25Ibid., 128-130.

26Ibid., 131-133. 


\section{KESIMPULAN}

STT kharisma menggunakan media radio yang ada untuk pemberitaan kabar baik bagi orang-orang yang ada di daerah-daerah dan juga bagi orang-orang (pendengar) yang sudah menggunakan media sosial. Dua wilayah ini yang disasar, dengan tujuan agar mereka mengenal Kristus dan akhirnya bertumbuh secara rohani. Untuk mencapai hal ini, STT kharisma membuat perencanaan pembelajaran yang terstruktur, sehingga setiap pendengar bisa mengerti, memahami dan dapat memprkatekkannya dalam kehidupan mereka sehari-hari. Melalui hal ini Sekolah Tinggi Teologi Kharisma Bandung telah berperan nyata dalam pengabdian kepada masyarakat sesuai dengan bidangnya.

\section{DAFTAR PUSTAKA}

Baskoro, Haryadi, and Hendro Hariyanto Siburian. "Keseimbangan Pertumbuhan Spiritual Dan Intelektual: Teladan Yesus Dan Paulus Bagi Hamba Tuhan Masa Kini." FIDEI: Jurnal Teologi Sistematika dan Praktika (2019).

Calvin Miller. Pola Hidup Kristen, Mengukur Pertumbuhan Kita. Bandung: Kalam Hidup, 2002.

Eugene Peterson. Pola Hidup Kristen, Bertumbuh Sebagai Orang Kristen Yang Sehat. Bandung: Kalam Hidup, 2002.

Evelyn Christenson. Pola Hidup Kristen, Berubah. Bandung: Kalam Hidup, 2002.

GUNAWAN, AGUNG. "PEMURIDAN DAN KEDEWASAAN ROHANI." SOLA GRATIA: Jurnal Teologi Biblika dan Praktika (2020).

Harjanto. Perencanaan Pengajaran. Jakarta: PT. Rangga Karya, 2008.

Horowski, Jarosław. "Christian Religious Education and the Development of Moral Virtues: A Neo-Thomistic Approach.” British Journal of Religious Education (2020).

Imeldawati, Tiur, and Yayan Erina Br. Regar. "Prinsip Pertumbuhan Rohani Dalam Efesus 5:1-21 Dan Korelasinya Dalam Mengupayakan Pertumbuhan Rohani Jemaat GPdI Gunung Moria Bedagai." Jurnal Christian Humaniora (2021).

KPI. “Survey Nielsen Indonesia 'Penetrasi Media,'” 2017.

Lase, Pieter. Katekisasi Umum Menyibak Tabir Kebenaran. Malang: Gandum Mas, 2014. Lebar, Lois E. Education That Is Christian (Proses Belajar Mengajar Kristiani \& Kurikulum Yang Alkitabiah). Edited by Tjuk S. Kaihatu. 2nd ed. Jakarta: Penerbit GAndum Mas, 2006.

Mika, Mika, and Petronella Tuhumury. "Implementasi Strategi Pembinaan Menuju Pertumbuhan Rohani Pemuda Gkii Jemaat Sidu'ung Muara Berau." Jurnal Jaffray (2013).

Telaumbanua, Arozatulo. "E-Misi : Aplikasi Penginjilan Berbasis Teknologi." Prodising (2020).

——_. "Peran Gembala Sidang Sebagai Pendidik Dalam Pertumbuhan Rohani Jemaat." FIDEI: Jurnal Teologi Sistematika dan Praktika (2019).

Yanto Paulus Hermanto. KATEKETIKA: BAGAIMANA GEREJA YANG MENUMBUHKAN ROHANI \& MENINGKATKAN PERAN MISI JEMAAT. 1st ed. Purwokerto: pena persada, 2021. 